\title{
Water Calculations in Billings
}

Shuo Zhang

North China Electric Power University(Bao Ding) ,Hebei 071000,China

735359890@qq.com

Keywords: water-recycle grey model cost-plus mode

\begin{abstract}
It is the purpose of the paper to develop a water-recycling plan for Billings.In this paper, I make two essential models and an extended model. I first develop grey model to predict the data of water use in the future 30 years at Billings. Grey model can well predict uncharted data and get an obvious trend.. Besides, I develop a cost-plus model to calculate the costs of water treatment both the non-potable and potable recycling systems. At last, I provide some suggestions about the water consummation at Billings.
\end{abstract}

\section{Introduction}

Billings is located in the south-central portion of Montana and is the county seat of Yellowstone County, also the biggest city in Montana. Billings has a semi-arid continental climate with dry, very warm summers, and cold, dry winters.[1] In recent years, due to the increase of the local population, global warming, El Nino and many other reasons, Billings is in deep trouble of water short. Beyond that, many other cities also have experienced a spate of dryness, especially in southwest America, which presents a challenge to the sustainability of current water use by human and natural systems in the region.[2]

I develop a water-recycling plan for Billings and there are three parts in the original problem statement.

\section{Assumptions}

Domestic water and industrial water are the mainly use in Billings. I neglect other kinds of water use.

Steps of getting non-potable water and potable are as follows: raw water is treated with flocculation aid and the coagulant. Next, the solids are allowed to precipitate. With the filtration of the filter tank and disinfection, I get non-potable water. Then, the non-potable water are filtered and disinfected further and potable water is produced. I neglect transportation costs.

\section{The Model 1: Grey Model}

Step1. Data examine and Processing: To guarantee the feasibility of the model, it is necessary to exam the known data. I have $x^{(0)}=\left(x^{(0)}(1), x^{(0)}(2), \ldots, x^{(0)}(n)\right)$, then calculate transmission $\lambda(k)$ :

$$
\lambda(k)=\frac{x^{(0)}(k-1)}{x^{(0)}(k)}, k=2,3, \ldots, n
$$

If all $\lambda(k)$ falls on $\Theta=\left(e^{-\frac{2}{n+1}}, e^{\frac{2}{n+2}}\right), x^{(0)}$ can be used as the data of the GM(1,1) model. Or else, $x^{(0)}$ will be transformed to make itself fall on $\Theta$. We are supposed to find suitable constant $c$ to make translation:

$$
y^{(0)}(k)=x^{(0)}(k)+c, k=1,2, \ldots, n
$$

Get $\lambda_{y}(k)=\frac{y^{(0)}(k-1)}{y^{(0)}(k)} \in \Theta, k=2,3, \ldots, n$ 
Step2. Building Model: Building GM(1,1) as equation(1), I can get the predicted values:

$x^{(1)}(k+1)=\left(X^{(0)}(1)-\frac{\hat{b}}{\hat{a}}\right) e^{-\hat{a k}}+\frac{\hat{b}}{\hat{a}}, k=0,1, \cdots, n-1, \cdots$

And

$$
\hat{x^{(0)}}(k+1)=\hat{x}^{(1)}(k+1)-\hat{x}^{(1)}(k), k=1,2, \cdots, n-1, \cdots
$$

\section{Step3. Testing the Predicted Value:}

(1) Testing Residue: Calculate $\varepsilon(k)$

$$
\varepsilon(k)=\frac{x^{(0)}(k)-\hat{x}^{(0)}(k)}{x^{(0)}(k)}, k=1,2, \ldots, n,
$$

$\hat{x}^{(0)}(1)=x^{(0)}(1)$, if $\varepsilon(k)<0.2$, it can be considered that the final results achieve accuracy Where $\hat{x}(1)=x^{(0)}(1)$, if $\varepsilon(k)<0.2$, it can be consi
generally. If $\varepsilon(k)<0.1$, it meets the high precision.[3]

(2)Testing Deviate Value: Calculate $\rho(k)$

$$
\rho(k)=1-\left(\frac{1-0.5 a}{1+0.5 a}\right) \lambda(k),
$$

If $\rho(k)<0.2$, it can be considered that the final results achieve accuracy generally. If $\rho(k)<0.1$, it meets the high precision.[4]

\section{Calculation Results of the Model}

The original data is into $\operatorname{GM}(1,1)$, then we can get results as follows:

Table 1

Data fitting

\begin{tabular}{lcc}
\hline year & $\begin{array}{c}\text { The demand of domestic } \\
\text { water(Mgal/d) }\end{array}$ & $\begin{array}{c}\text { The demand of industrial } \\
\text { water(Mgal/d) }\end{array}$ \\
\hline 2016 & 16.33364 & 11.1211 \\
2017 & 16.4657 & 11.2074 \\
2018 & 16.59882 & 11.2945 \\
2019 & 16.73301 & 11.3822 \\
2020 & 16.86829 & 11.4706 \\
2021 & 17.00467 & 11.5596 \\
2022 & 17.14215 & 11.6494 \\
2023 & 17.28074 & 11.7399 \\
2024 & 17.42045 & 11.831 \\
2025 & 17.56129 & 11.9229 \\
2026 & 17.70326 & 12.0155 \\
2027 & 17.84639 & 12.1088 \\
2028 & 17.99067 & 12.2029 \\
2029 & 18.13612 & 12.2976 \\
2030 & 18.28275 & 12.3931 \\
\hline
\end{tabular}



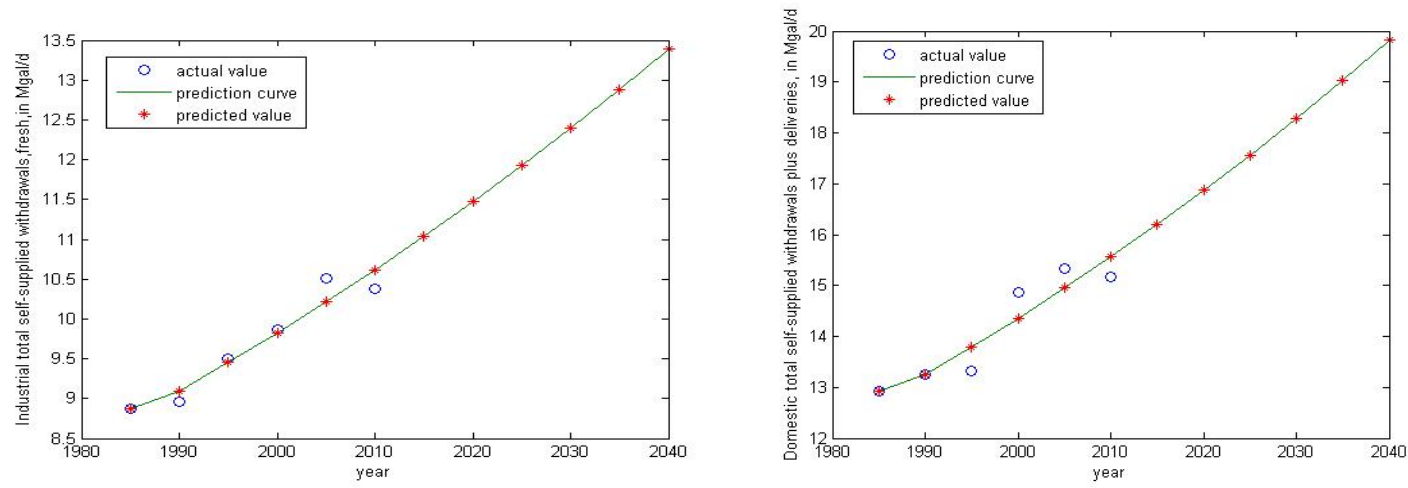

Model 2: Costs of water recycling

Table 2.Model 2 parameters

\begin{tabular}{ll}
\hline Parameter & Meaning \\
\hline $\boldsymbol{Q}_{1}$ & The demand for non-potable water of reclaimed water \\
$\boldsymbol{Q}_{2}$ & The demand for potable water of reclaimed water \\
$\boldsymbol{S}_{1}$ & The non-potablewater plantsinvestment costs \\
$\boldsymbol{S}_{2}$ & The potable waterplantsinvestment costs \\
$\boldsymbol{C}_{\mathbf{1}}$ & Annual depreciation charge for Construction project investment \\
& of recycle water \\
$\boldsymbol{C}_{2}$ & Reclaimed water management fee per year \\
$\boldsymbol{k}_{1}$ & Fixed assets depreciation rates \\
$\boldsymbol{k}_{2}$ & Correction coefficient \\
$\boldsymbol{k}_{3}$ & Cost factor of repair \\
$\boldsymbol{E}_{\boldsymbol{1}}$ & Power bill \\
$\boldsymbol{E}_{\mathbf{2}}$ & Pharmaceutical costs \\
$\boldsymbol{E}_{3}$ & Repair and maintenance costs \\
$\boldsymbol{E}_{\mathbf{4}}$ & Wages and benefits \\
$\boldsymbol{M}_{\mathbf{1}}$ & Costs of producing non-potable water for each unit \\
$\boldsymbol{M}_{\mathbf{2}}$ & Costs of producing potable water for each unit \\
$\boldsymbol{a}_{\boldsymbol{i}}$ & Dosage of the i th chemical \\
$\boldsymbol{b}_{\boldsymbol{i}}$ & The price of drug i unit dose \\
$\mathbf{n}$ & Types of chemicals needed \\
\hline
\end{tabular}

\section{Step1: Investment of reclaimed Wastewater Treatment Plant}

Step 2: Costs of water management

$$
C_{1}=k_{1} Q^{\alpha}
$$

$$
C_{2}=E_{1}+E_{2}+E_{3}+E_{4}
$$

Where $E_{1}=k_{2} e Q H, E_{2}=\frac{365 Q}{10^{3}} \sum_{i=1}^{n}\left(a_{i} b_{i}\right), E_{3}=k_{3} E_{1}, E_{4}=\left(C_{1}+E_{1}+E_{2}+E_{3}\right) \times k_{4}$

The costs of reclaimed water is $S$

$$
S=C_{1}+C_{2}
$$

\section{Step 3: Costs of both water:}

$$
\begin{gathered}
M_{1}=\frac{Q_{1}}{Q_{1}+Q_{2}} S_{1} \\
M_{2}=\frac{Q_{2}}{Q_{1}+Q_{2}} S_{1}+S_{2}
\end{gathered}
$$




\section{Sensitivity}

Based on the results of Model 1, the water use in 2015 is into Model 2 to calculate $C_{1}, E_{1}, E_{2}, E_{3}, E_{4}$ and $S$, where $k_{1}=0.05, k_{2}=1.15, k_{3}=0.025, k_{4}=0.15, e=1.00$. [5]Then I modified parameter values by $10 \%$ and get the following results.

\begin{tabular}{lll}
\multicolumn{2}{c}{ Table 3.Sensitivity of costs of reclaimed water to $\pm 10 \%$ change in parameter values } \\
\hline Parameter & Percentage change in costs of reclaimed water in \\
\cline { 2 - 3 } & $+10 \%$ in parameter & $-10 \%$ in parameter \\
\hline $\mathrm{Q}$ & $9.98 \%$ & $-9.98 \%$ \\
$k_{1}$ & $0.0977 \%$ & $-0.0977 \%$ \\
$k_{2}$ & $9.72 \%$ & $-9.72 \%$ \\
$k_{3}$ & $0.24 \%$ & $-0.24 \%$ \\
$k_{4}$ & $1.3 \%$ & $-1.3 \%$ \\
\hline
\end{tabular}

\section{Conclusion}

From the figure and table, I know our model can well fit the raw data. Both the domestic and industrial water use present an increasing trend. Billings will consume more and more water if it develops still at current situation.According to exact data, I can get the costs of two kinds of water systems. And by the analysis of sensitivity, I know our model has a good stability.

\section{Reference}

[1] https://en.wikipedia.org/wiki/Billings,_Montana

[2] Daniel R. Cayan, Tapash Das, David W. Pierce, Tim P. Barnett, Mary Tyree, and Alexander Gershunov. Future dryness in the southwest US and thehydrology of the early 21st century drought.United StatesGeological Survey, La Jolla, CA 92093-0224.

[3]Jeffery Forrest, Zaiwu Gong, Tianxiang Yao.Grey Systems: Theory and Application. Emerald Group Publishing Limited

[4] Erdal Kayacan, Baris Ulutas, Okyay Kaynak. Grey system theory-based models in time series prediction. Expert Systems with Applications $37 \quad$ (2010) $1784 \quad$ - 1789. http://dx.doi.org/10.1108/20439371211197622.

[5] Colette L. Meehan. Fixed Price Vs. Cost Plus. http://smallbuisiness.chron.com/fixed-price-vs-cost-plus-2220.html. 